\title{
HYALINE BODIES ON THE DISCS
}

BY

\author{
F. C. Plummer \\ LIVER POOL
}

THIS painting is of the discs of a boy, aged 10 years, referred by his school for defective vision.

R. vision with +2.5 D. sph. $=6 / 6$ partly $\}$ both eyes together

L. vision with $+2 \cdot 5$ D. sph. $=6 / 6$ partly $\}=6 / 6$ fully.

The visual fields were slightly but regularly contracted. Five months later no further change was to be seen. Both discs showed,

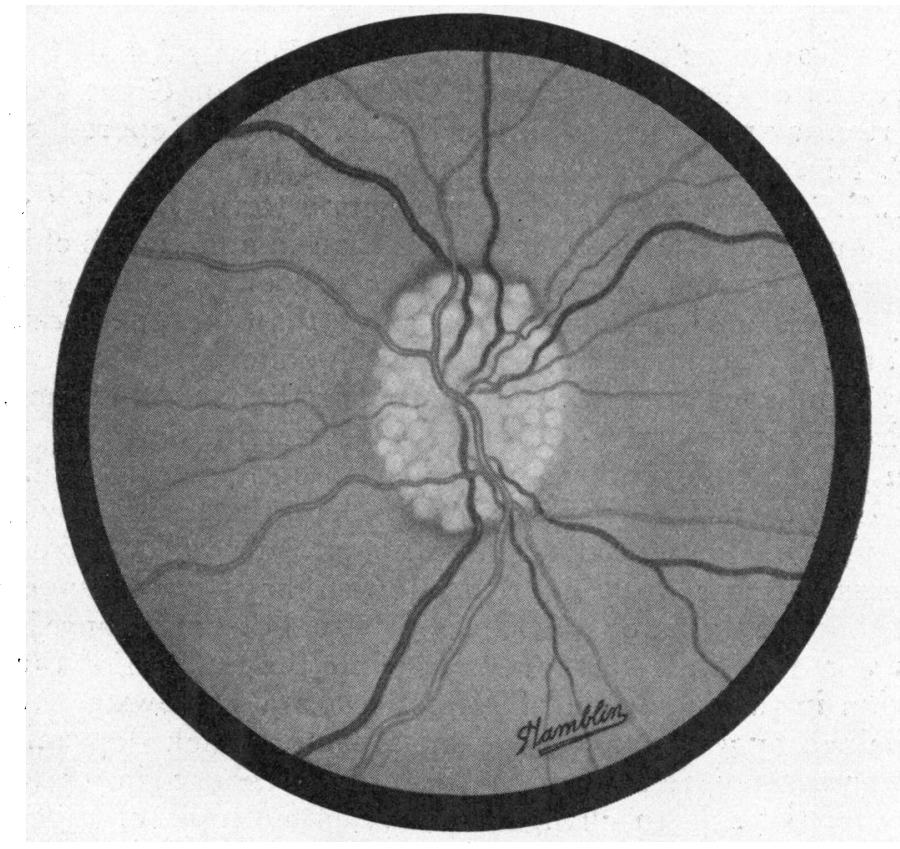

to an equal extent, marked hyaline bodies, which overlapped the margins.

The picture does not show up in sufficient relief the small "sagograin-like" appearance of the hyaline bodies.

The boy is healthy and the third in a family of five and except for a severe attack of scarlet fever at six years old, there is nothing of importance in his history.

There is nothing in the family history and no record of any 
ocular disease. The other members of the family that were examined showed no changes in the fundi.

This case was shown at the North of England Ophthalmological Society but no member had seen a similar case before and this is my excuse for submitting this drawing for publication.

The most exhaustive account in the literature seems to be in Vol. II, pp. 661 et seq. of Parsons, Pathology of the Eye.

\section{ANNOTATION}

\section{The Normal Refraction in Infancy and its bearing} on the development of Myopia

An investigation on this subject was undertaken, by Arnold Sorsby, at the request of the Jewish Health Organization of Great Britain; and the results are presented in the L.C.C. Annual Report for 1933 (Vol. IV, Part III, p. 55) just published.

The L.C.C. has repeatedly drawn attention to the fact that visual defect is much more frequent in Jewish than in non-Jewish children at the age of 14 years when pupils leave school. Defective vision among Jews is also heavier on the boys than on the girls, theo reverse of what occurs among non-Jewish children.

Sorsby's previous attempt " to disentangle the factors of race, sex and environment in the causation of a heavier incidence of visual defect in Jewish children" was published in our columns (Vol. XII, p. 197, 1928). His results confirmed the greater prevalence of visual defect in Jewish boys; but did not substantiate the view that excessive close-work done by Jewish boys was responsible. He held that the "greater prevalence of visual defect among Jewish children was due to a racial variation, while the reversal of the sexdistribution in the incidence of refractive error in Jewish children was explained by a sex-linked non-racial factor which determines a greater increase of refraction in the case of boys; in them the tendency for the eyes to change towards emmetropia or myopia is therefore greater, and with more Jewish boys having a low hypermetropic reserve, the greater incidence of myopia among Jewish children at the school-leaving age could be thus explained."

This paper dealt with selected material.

Miss Mcllroy, investigating for the L.C.C. (Annual Report for 1928 , Vol. III, p. 86), could not substantiate the presence of a lower hypermetropic reserve in Jewish children; she also found that low myopia, absent at the age of seven years, increases during school life in all groups, but to a far greater extent among Jewish children, both boys and girls, than among gentile children. Her 